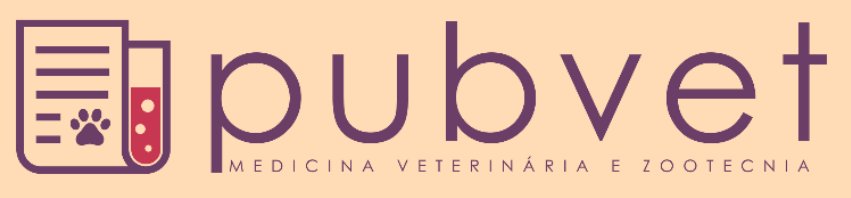

https://doi.org/10.31533/pubvet.v14n2a505.1-11

\title{
Prevalência soroepidemiológica de Leptospira spp. em rebanhos bovinos leiteiros da mesorregião do Rio Doce no Estado do Espírito Santo
}

\author{
André Eller Baroni ${ }^{1}$, Gabriella Bossanelli ${ }^{1 \oplus}$, Rithielli Boening Boelcke ${ }^{1 \oplus}$, Leonardo Campos Almeida ${ }^{1 * \odot}$
}

${ }^{I}$ Escola Superior São Francisco de Assis, Curso de Medicina Veterinária, Santa Teresa, Espírito Santo, Brasil.

*Autor para correspondência, E-mail: leocamposalmeida@hotmail.com

\begin{abstract}
Resumo. Objetivou-se investigar a prevalência e os fatores de risco da Leptospirose em rebanhos bovinos leiteiros da mesorregião do Rio Doce, ES, composta por seis municípios: Aracruz, Ibiraçu, João Neiva, Linhares, Rio Bananal e Sooretama. As propriedades foram sorteadas aleatoriamente, sendo duas propriedades por município. Admitiu-se como critério de seleção destas propriedades por não apresentarem o manejo de realização da vacinação anti-Leptospira nos animais. O número de amostras sanguíneas em cada propriedade foi de acordo com a disponibilidade de animais, que totalizou 100 amostras de sangue. A técnica sorológica utilizada foi a de Soroaglutinação Microscópica (SAM). As amostras de soro foram submetidas a diluições com 10 (dez) antígenos vivos que inclui os sorovares: L. australis, L. butembo, L. copenhageni, L. bratislava, L. canicola, $L$. grippothyphosa, L. hardjo prajitno, L. pomona, L. icterohaemorrhagiae, L. Wolffi do gênero Leptospira spp. da espécie interrogans. A prevalência dos sorovares neste estudo foi de Wolffi (24\%); Bratislava (15\%); Hardjo prajitno (11\%); Pomona (10\%); Butembo (10\%); Australis (8\%); Canicola (5\%); Icterohaemorragiae (5\%); Grippotyphosa (4\%); Copenhageni (3\%). Os resultados demonstram que a Leptospirose bovina está presente na mesorregião com $50 \%$ de prevalência em indivíduos, sendo os principais fatores de risco a não vacinação, presença de roedores, criação conjunta e rebanho aberto.
\end{abstract}

Palavras chave: leptospirose, manejo, sorovares

\section{Seroepidemiological prevalence of Leptospira spp. in dairy cattle herds of the Doge River region in the State of Espirito Santo}

\begin{abstract}
The objective of this study was to investigate the prevalence and risk factors of Leptospirosis in dairy herds of the Rio Doce, ES, composed of six municipalities: Aracruz, Ibiraçu, João Neiva, Linhares, Rio Bananal and Sooretama. The properties were randomly selected, with two properties per municipality. It was admitted as a criterion for selecting these properties because they did not present the management of anti-Leptospira vaccination in the animals. The number of blood samples in each property was according to the availability of animals, which totaled 100 blood samples. The serological technique used was Microscopic Soroagglutination (SAM). Serum samples were submitted to dilutions of 10 (ten) live antigens, including the serovars $L$. australis, $L$. butembo, L. copenhageni, L. bratislava, L. canicola, $L$. grippothyphosa, L. hardjo prajitno, L. L. pomol, L. icterohaemorrhagiae, L. Wolffi of the genus Leptospira spp. of the species interrogans.The prevalence of serovars in this study was from Wolffi (24\%); Bratislava (15\%); Hardjo prajitno (11\%); Pomona (10\%); Butembo (10\%); Australis (8\%); Canicola (5\%); Ichterohaemorragiae (5\%); Grippotyphosa (4\%); Copenhageni (3\%). The results demonstrate that bovine Leptospirosis is present in the mesoregion with $50 \%$ prevalence in individuals, the main risk factors being non-vaccination, presence of rodents, joint breeding and open herd.
\end{abstract}


Keywords: leptospirosis, management, serovars

\title{
Prevalencia seroepidemiológica de Leptospira spp. en rebaños de ganado lechero de la mesorregión de Río Doce en el estado de Espíritu Santo
}

\begin{abstract}
Resumen. El objetivo de este estudio fue investigar la prevalencia y los factores de riesgo de la leptospirosis en rebaños de ganado lechero de la mesorregión del río Doce, ES, compuesto por seis municipios: Aracruz, Ibiraçu, João Neiva, Linhares, el río Bananal y Sooretama. Las propiedades se sortearon, con dos propiedades por municipio. Se aceptó como criterio de selección de estas propiedades por no presntar el manejo de la vacunación contra Leptospira en animales. El número de muestras de sangre en cada propiedad fue de acuerdo con la disponibilidad de animales, que totalizaron 100 muestras de sangre. La técnica serológica utilizada fue la seroaglutinación microscópica (SAM). Las muestras de suero se diluyeron con 10 (diez) antígenos vivos, incluidos los serotipos: L. australis, $L$. butembo, L. copenhageni, L. bratislava, L. canicola, L. grippothyphosa, L. hardjo prajitno, L. pomona, L. icterohaemorrhagiae, L. Wolffi del género Leptospira spp. de las especies interrogans. La prevalencia de serovares en este estudio fue Wolffi (24\%); Bratislava (15\%); Hardjo prajitno (11\%); Pomona (10\%); Butembo (10\%); Australis (8\%); Canicola (5\%); Icterohaemorragiae (5\%); Grippotyphosa (4\%); Copenhageni (3\%). Los resultados muestran que la leptospirosis bovina está presente en la mesorregión con una prevalencia del $50 \%$ en los individuos, siendo los principales factores de riesgo la no vacunación, la presencia de roedores, la cría conjunta y el rebaño abierto.
\end{abstract}

Palabras clave: leptospirosis, manejo, serovares

\section{Introdução}

O Estado do Espirito Santo se destaca por possuir um rebanho bovino de 1,93 milhões de cabeças (ANUALPEC, 2019). A pecuária leiteira do estado produz anualmente 500 mil toneladas de leite e está entre as três principais atividades com maior participação no valor bruto da produção agropecuária capixaba, segundo o Instituto Capixaba de Pesquisa, Assistência Técnica e Extensão Rural - INCAPER (ESPÍRITO SANTO, 2018b).

A Leptospirose é uma zoonose bacteriana, infectocontagiosa que acomete seres humanos e animais. Causada por qualquer espécie patogênica de bactérias do gênero Leptospira spp. (Figueiredo et al., 2009) sendo as mais comuns a L. interrogans e a L. borgpetersenii (Nicolino et al., 2014; Quinn et al., 2005).

A sintomatologia da doença varia de acordo com o sorovar infectante e da suscetibilidade do animal (Marinho, 2012). Alguns indivíduos podem apresentar-se assintomáticos (Guimarães et al., 2014; Hagiwara et al., 2015) e outros podem apresentar quadros de abortos, nascimento de bezerros debilitados, natimortos, retorno ao cio, infertilidade e queda na produção de leite (Sarmento et al., 2012). O diagnóstico da Leptospirose é baseado em achados clínicos apresentados pelos animais. Todavia, essa sintomatologia é semelhante a outras doenças reprodutivas, por isso se faz necessário realizar o exame laboratorial para um correto diagnóstico (Banchiero Júnior et al., 2014).

No Brasil, nos estudos sorológicos realizados relacionados à doença nos bovinos, identificaram que a infecção se encontra vastamente distribuída no país (Banchiero Júnior et al., 2014; Pimenta et al., 2014; Reis et al., 2017). Dentre os sorovares mais encontrados em bovinos destacam-se: Hardjo, Wolffi, Pomona, Grippotyphosa, Icterohaemorrhagiae e Canicola. Onde o sorovar Hardjo apresenta-se com maior prevalência (Coelho et al., 2014; Oliveira et al., 2013).

Considerando a abertura de mercados no segmento de laticínios no estado do Espírito Santo e a importância socioeconômica que a Leptospirose Bovina representa (Fassio et al., 2006; Lopes et al., 2012), objetivou-se com o presente estudo determinar a prevalência dos sorovares predominantes e os fatores de risco associados à presença da Leptospira spp. em vacas leiteiras da mesorregião do Rio Doce no Estado do Espírito Santo. 


\section{Material e métodos}

Área de estudo

O trabalho foi realizado na mesorregião do Rio Doce, no Estado do Espirito Santo, Brasil, composta por seis municípios: Aracruz, Ibiraçu, João Neiva, Linhares, Rio Bananal e Sooretama (Figura 1). Todos esses municípios possuem clima tropical, com precipitação pluviométrica média anual de $1.100 \mathrm{~mm}$ e temperatura média anual variando de 11 a $34^{\circ} \mathrm{C}$ (ESPÍRITO SANTO, 2018c).

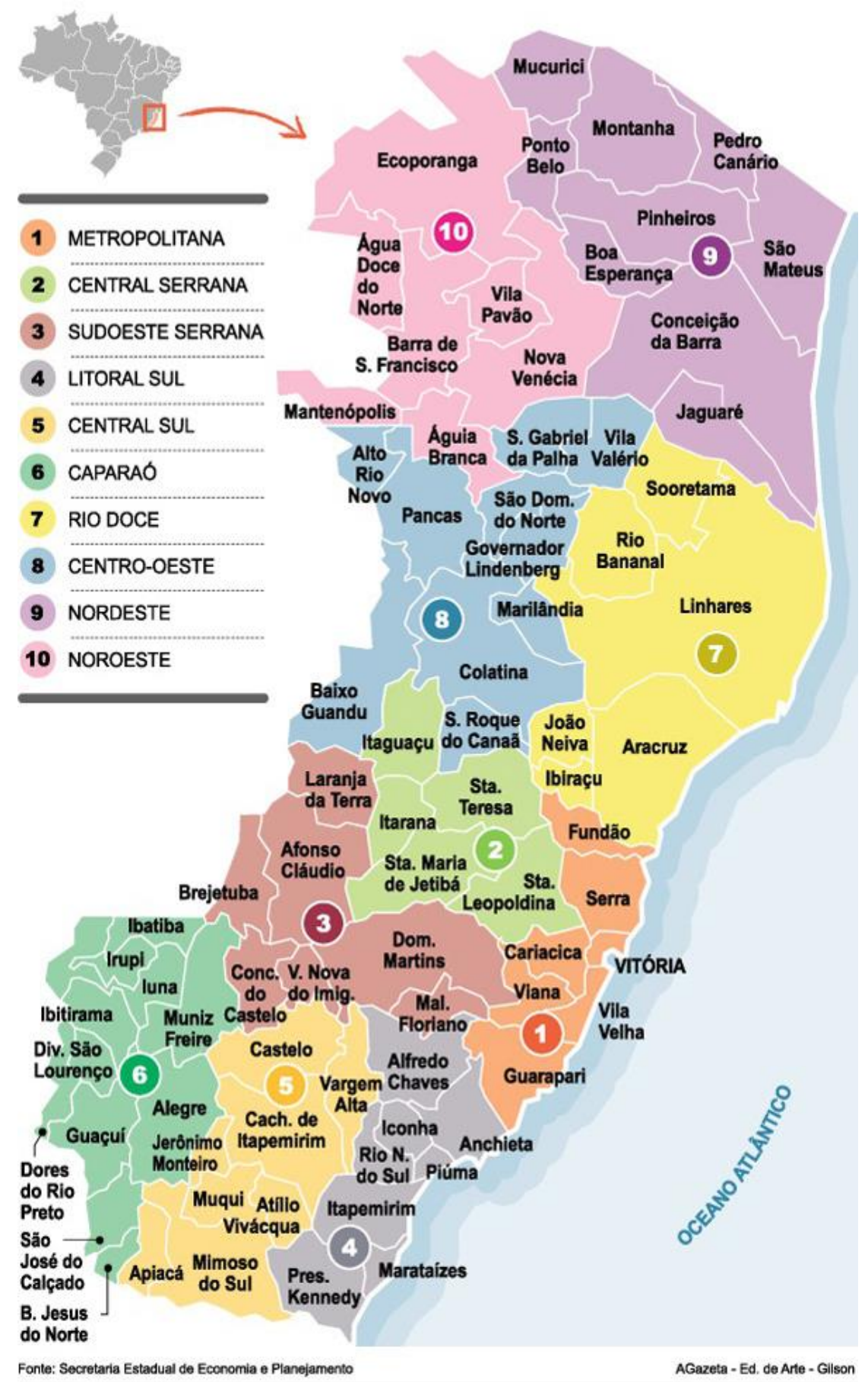

Figura 1. Mesorregiões do estado da Espírito Santo, Brasil (ESPÍRITO SANTO, 2018a).

Seleção dos rebanhos e animais

Todas as propriedades rurais utilizadas no presente estudo são produtoras de leite, concomitantes ou não a outras atividades. Utilizou-se para seleção das propriedades um Delineamento Inteiramente 
Casualizado, dada a homogeneidade do rebanho e das características ambientais entre as Unidades Experimentais (UE). Foram escolhidas por sorteio duas propriedades por município. Além disso, admitiu-se como critério de prévia seleção das UE a prerrogativa de apresentarem ou não manejo de vacinação contra Leptospiroses.

\section{Amostragem}

Foram coletadas entre 12 a 20 amostras de sangues em cada região sorteada de acordo com a disponibilidade de animais. Totalizaram-se assim, 100 amostras de sangue provenientes da mesorregião do Rio Doce (Tabela 1).

Tabela 1. Distribuição da Mesorregião Rio Doce com os municípios, número de rebanhos e amostras coletadas.

\begin{tabular}{llcc}
\hline Unidade Regional & Municípios & $\mathrm{N}^{\circ}$ de Rebanhos & $\mathrm{N}^{\circ}$ de Amostras \\
\hline \multirow{4}{*}{ Rio Doce } & Sooretama & 2 & 18 \\
& Linhares & 2 & 18 \\
& Rio Bananal & 2 & 20 \\
& Aracruz & 2 & 18 \\
Total & Ibiraçu & 2 & 12 \\
\hline
\end{tabular}

Todas as amostras foram submetidas ao teste de Soroaglutinação Microscópica para os sorovares específicos de Leptospira ssp.

Foram utilizadas fêmeas bovinas em idade reprodutiva (acima de 24 meses), com aptidão leiteira (n $=100$ ). Não foram incluídos na amostragem para coleta de material biológico, animais sem conhecimento de histórico de aquisição. Esta conduta deveu-se pela necessidade da exclusão de resultados falso-positivos provenientes de animais que poderiam ter sido vacinados anteriormente (Paixão et al., 2016; Pimenta et al., 2014).

Cada propriedade foi identificada com o nome da mesma e um número em ordem crescente. A identificação dos animais foi realizada através de fotos e números, no qual o primeiro algarismo que indica o número do animal deve ser o número de identificação da propriedade (ex.: número da propriedade: 1, número dos animais da propriedade em questão: 1.0, 1.1, 1.2, 1.3, 1.4, 1.5 etc). As amostras devem ser identificadas com o número do animal à qual pertence, contendo desta forma a identificação da propriedade.

As propriedades amostradas se caracterizavam como: pequenas $(n=4)$, médias $(n=3)$ e grandes $(n=5)$, com variação de seis a 470 animais. As condições gerais do rebanho quanto ao escore de condição corporal eram boas e medianas. Quanto à raça, as principais encontradas foram: Girolanda e Mestiço (Zebu e Holandês). No sistema de produção quatro propriedades utilizavam semi-confinamento e as demais sistema extensivo a pasto. Quanto às condições das pastagens foram verificadas boas condições de cobertura. Os sistemas de ordenha encontrados nas propriedades foram manuais $(n=3)$ e mecânicas $(n=9)$.

\section{Coleta das amostras}

As amostras foram colhidas durante o período de agosto a setembro de 2018. Foram coletadas amostras de $5 \mathrm{ml}$ de sangue por meio de punção da veia mamária logo após o momento da ordenha, evitando estresse dos animais durante a mesma. O método de coleta foi asséptico com desinfecção do local com algodão hidrófilo e álcool $70 \%$ e por sistema fechado em tubos Vaccutainer sem anticoagulante.

O material foi transportado refrigerado $\left(2\right.$ a $\left.8^{\circ} \mathrm{C}\right)$, acondicionado em caixa isotérmica e enviado ao Laboratório da Escola Superior São Francisco de Assis - ESFA com prazo de 24 horas e centrifugado a $2.500 \mathrm{rpm}$, durante 5 minutos. Em seguida, as amostras de soro foram acondicionadas em tubos plásticos tipo Eppendorf e congeladas a $-20^{\circ} \mathrm{C}$, e posteriormente enviadas ao Laboratório Axys Análises localizado em Porto Alegre/RS, para a realização do exame sorológico. 


\section{Técnica sorológica}

A técnica sorológica utilizada foi a de SAM, que se baseia na detecção de imunoglobulinas específicas - IgM para detecção do antígeno para Leptospira. A utilização da IgM justifica-se uma vez que esta é a mais detectada nesse teste comparada a $\operatorname{IgG}$, devido a sua alta especificidade em quadros agudos da doença. Assim, um animal que possivelmente veio ser vacinado ou se infectado da bactéria anteriormente não acusará nesse teste sorológico o resultado positivo, pelo fato de apresentar imunoglobulinas IgG. As amostras de soro foram submetidas a diluições com 10 (dez) antígenos vivos que inclui os sorovares: L. australis, L. butembo, L. copenhageni, L. bratislava, L. canicola, $L$. grippothyphosa, L. hardjo prajitno, L. pomona, L. icterohaemorrhagiae, L. wolffi do gênero Leptospira spp. da espécie interrogans.

Para as reações positivas foi considerada a presença de aglutinação microscópica em campo escuro. O critério para classificação do grau de aglutinação foi de acordo com a \% de Leptospiras aglutinadas, sendo a leitura de reações como positivas com (+) se interpreta 1/100; reações (++) se interpreta 1/200; reações (+++) se interpreta $1 / 400$ e reações (++++) se interpreta 1/800, conforme a carga bacteriana.

\section{Aplicação do questionário epidemiológico}

Foi realizado um questionário ( $\underline{\text { Anexo }}$ ) para o recolhimento de informações para o estudo epidemiológico da Leptospirose Bovina na região. Para cada propriedade rural os proprietários responderam perguntas referentes aos pontos determinantes da doença como: protocolo vacinal, tipo de criação e alimentação, prevalência de doenças reprodutivas, manejo reprodutivo; e fatores de risco como: presença de roedores e criação conjunta (Banchiero Júnior et al., 2014; Paixão et al., 2016; Viana et al., 2010).

\section{Planejamento estatístico/delineamento experimental}

No presente estudo foi utilizado o Delineamento Inteiramente Casualizado. Para obtenção dos resultados estatísticos foi calculada a prevalência sorológica mediante cálculo de porcentagem (\%) de animais positivos no rebanho total e a porcentagem por sorovar no rebanho positivo.

\section{Resultados}

Encontrou-se no presente estudo prevalência de 50\% $(\mathrm{n}=50)$ de animais reagentes para pelo menos um sorovar dentro da coleção de 10 testados do gênero Leptospira spp. em rebanhos distintos na mesorregião do Rio Doce (Tabela 2).

Tabela 2. Prevalência dos animais reagentes / positivos ao teste de Soroaglutinação Microscópica por município, da mesorregião do Rio Doce/ES.

\begin{tabular}{lccc}
\hline \multirow{2}{*}{ Município } & \multirow{2}{*}{$\mathrm{N}^{\mathbf{0}}$ de Animais Coletados } & \multicolumn{2}{c}{$\mathrm{N}^{\mathbf{0}}$ de Animais Reagentes } \\
\cline { 3 - 4 } Rio Bananal & 20 & 12 & 60 \\
Sooretama & 18 & 9 & 50 \\
Linhares & 18 & 10 & 55,5 \\
Ibiraçu & 12 & 6 & 50 \\
Aracruz & 18 & 6 & 33,3 \\
João Neiva & 14 & 7 & 50 \\
Total & 100 & 50 & $\chi 50$ \\
\hline
\end{tabular}

Dentro das amostras de soro examinadas, o quantitativo das reações positivas segundo a titulação foram: $1 / 100(\mathrm{n}=83), 1 / 200(\mathrm{n}=10), 1 / 400(\mathrm{n}=2)(\underline{\text { Tabela 3 }})$.

\section{Discussão}

A prevalência de soropositividade para Leptospira spp. encontradas nos rebanhos bovinos avaliados no estudo, corroboram com os valores encontrados por Banchiero Júnior et al. (2014) em trabalho realizado na zona rural do município de Guaíra /SP, onde a taxa de prevalência encontrada correspondeu a 46,15\%. 
No entanto, outros autores encontraram taxa de prevalência acima das encontradas no presente experimento, como o realizado por Pimenta et al. (2014) com prevalência de 89,7\%, no estado da Paraíba, Tonin et al. (2010), em Santa Catarina com 65,5\% de animais positivos, Sarmento et al. (2012) 59,12\% de positividade na SAM, em estudo realizado em oito estados brasileiros: GO, MS, MT, MG, PR, RS, SC e SP e Coelho et al. (2014), no município de São Luís/MA, encontraram prevalência de 64\% de reações positivas.

Tabela 3. Números de reagentes ao teste de Soroaglutinação Microscópica, de acordo com as sorovares e seus respectivos títulos, na mesorregião do Rio Doce/ES.

\begin{tabular}{lcccccc}
\hline \multirow{2}{*}{ Sorovares } & \multicolumn{7}{c}{ Título } \\
\cline { 2 - 7 } & \multicolumn{3}{c}{100} & \multicolumn{2}{c}{200} & \multicolumn{2}{c}{400} \\
\hline L. Wolffi & 20 & $24,09 \%$ & 2 & $20 \%$ & 2 & $100 \%$ \\
L. Bratislava & 10 & $12,04 \%$ & 5 & $50 \%$ & 0 & $0 \%$ \\
L. Hardjo prajitno & 9 & $10,84 \%$ & 2 & $20 \%$ & 0 & $0 \%$ \\
L. Butembo & 9 & $10,84 \%$ & 1 & $10 \%$ & 0 & $0 \%$ \\
L. Pomona & 10 & $12,04 \%$ & 0 & $0 \%$ & 0 & $0 \%$ \\
L. Australis & 8 & $9,63 \%$ & 0 & $0 \%$ & 0 & $0 \%$ \\
L. Canicola & 5 & $6,02 \%$ & 0 & $0 \%$ & 0 & $0 \%$ \\
L. Icterohaemorrhagiae & 5 & $6,02 \%$ & 0 & $0 \%$ & 0 & $0 \%$ \\
L. Grippotyphosa & 4 & $4,81 \%$ & 0 & $0 \%$ & 0 & $0 \%$ \\
L. Copenhageni & 3 & $3,61 \%$ & 0 & $0 \%$ & 0 & $0 \%$ \\
\hline Total & 83 & $100 \%$ & 10 & $100 \%$ & 2 & $100 \%$ \\
\hline
\end{tabular}

*Frequência dos animais reagentes.

Existem relatos de prevalências superiores a $90 \%$ encontrados em estudos, como o descrito por Figueiredo et al. (2009) com 90,4\%, no estado do Mato Grosso do Sul. Homem et al. (2001) em Uruará, Pará, a prevalência sorológica da Leptospirose bovina foi de 97\%. Miashiro et al. (2018) no Pantanal, a prevalência dos rebanhos foi de $98 \%$. Paixão et al. (2016) em estudo realizado nos municípios das bacias leiteiras do estado do Maranhão, apresentou alta prevalência de $100 \%$.

A prevalência encontrada no presente experimento para os sorovares investigados foi: Wolffi (24\%); Bratislava (15\%); Hardjo prajitno (11\%); Butembo (10\%); Pomona (10\%); Australis (8\%); Canicola (5\%); Icterohaemorragiae (5\%); Grippotyphosa (4\%); Copenhageni (3\%) (Figura 2).



Figura 2. Distribuição dos sorovares anti-Leptospira interrogans em 50 soros bovinos positivos, das Mesorregiões do Rio Doce, Espirito Santo, 2018.

Os resultados aqui encontrados foram superiores aos observados nos estudos de Silva et al. (2012) no qual a prevalência foi de 35,94\%, no estado do Maranhão. Viana et al. (2010) em estudo na região do Caparaó 
no estado do ES, encontraram prevalência de 12,42\%. Nicolino et al. (2014) em estudo realizado em 11 municípios da região de Sete Lagoas, MG a prevalência foi de 20,7\% e Ferreira et al. (2017) no estado do Piauí, seus estudos revelaram uma prevalência de 32,8\% em fêmeas bovinas.

Nos estudos de Tonin et al. (2010) os sorovares Hardjo (31,4\%) e Wolffi (10,9\%), apresentaram-se como os de maior prevalência. No entanto, observou-se aumento do sorovar Butembo $(8,4 \%)$ nos rebanhos bovinos no Estado de Minas Gerais. Sendo considerado um sorovar de baixa prevalência até o presente momento encontrado na maioria dos estudos, os resultados desta pesquisa com o sorovar Butembo foi de $10 \%$, valor considerado elevado, obtendo resultados semelhantes a este autor. A elevada taxa do sorovar Hardjo no rebanho bovino é relatada nos trabalhos em muitas regiões do Brasil (Miashiro et al., 2018). Isto pode ser explicado pelas formas de manejo e sanidade do rebanho e ambiente. A deficiência dos produtores de não realizarem a vacinação, de adquirirem animais de outras localidades facilita que este sorovar apresente fácil disseminação direta entre bovinos e leptospiroses (Figueiredo et al., 2009). Embora haja predominância nos demais estudos pelo sorovar Hardjo, neste estudo, o sorovar Wolffi que apresentou prevalência superior os demais (24\%). Nos estudos de Banchiero Júnior et al. (2014) no município de Guaíra - SP, Wolffi apresentou-se com prevalência de 19,8\%; Sarmento et al. (2012) no estudo em oito estados em Minas Gerais, teve prevalência de 7,91\%; Paixão et al. (2016) com 79\%, Silva et al. (2012) com 22\% e Coelho et al. (2014) com 4\% estes no estado do Maranhão e Figueiredo et al. (2009) no Mato Grosso do Sul com 12,3\%. Nos estudos de Viana et al. (2010) na região do Caparaó no estado do Espirito Santo 19,51\% reagiram frente ao sorovar Wolffi.

Neste estudo o sorovar Bratislava apresentou-se como a segunda maior prevalência (15\%) nos animais reagentes. Segundo Homem et al. (2001) o sorotipo Bratislava já foi descrito por muitos autores como causador da Leptospirose clínica. Já se verificaram títulos em bovinos e em outras espécies, como equinos, suínos, caninos, ratos silvestres, guaxinins e bisões. Pode também causar quadros clínicos no homem, assim como o sorovar Grippotyphosa, que neste estudo apresentou prevalência de 4\%. Segundo Ferreira et al. (2017) a prevalência alta do sorovar Icterohaemorrhagiae encontrada em seu estudo pode estar relacionado à saúde pública, principalmente pela presença de roedores. No presente estudo, todos os rebanhos que apresentaram a prevalência do sorovar Icterohaemorragiae também havia a presença de roedores nas propriedades. Conforme os estudos de Juliano et al. (2000); Figueiredo et al. (2009); Sarmento et al. (2012) e Coelho et al. (2014) afirmam que possa existir reações cruzadas entre os sorovares Wolffi e Hardjo, devido ao fato de ambos pertencerem ao sorogrupo Sejroe. Nos estudos de Juliano et al. (2000) o rebanho da microrregião de Goiânia, obteve prevalência de apenas 5,20\% para Hardjo, sendo superior a prevalência do sorovar Wolffi $(36,1 \%)$. Portanto, compatível aos resultados deste estudo onde a prevalência de Wolffi foi superior à de Hardjo, 24\% e 11\%, respectivamente.

Essa semelhança nos vários estudos que apresentaram altos resultados de prevalência da Leptospirose em bovinos indicam a necessidade da tomada de medidas profiláticas contra a doença (Pimenta et al., 2014). Dentre as práticas a serem usadas, a vacinação é a que apresenta maior eficácia, desde que esta tenha a maioria dos sorovares comuns de patogenia nos bovinos. Com isso, a ocorrência de perdas econômicas ocasionados por esta enfermidade tende a diminuir segundo Pimenta et al. (2014).

Com os dados obtidos através da realização do questionário (Anexo) para recolhimento de informações para estudo epidemiológico da Leptospirose bovina na microrregião do Rio Doce, foi possível identificar os possíveis fatores de risco de acordo com o manejo dos animais e ambiente (Tabela 4).

Dentre os rebanhos amostrados neste estudo, as queixas relatadas pelos proprietários eram: o histórico de presença de animais que apresentavam sintomatologia clínica de emagrecimento, leve grau de anemia, baixa produção de leite e principalmente problemas reprodutivos tais como aborto, repetição de cio e baixa taxa de prenhez.

A atuação dos médicos veterinários que exercem assistência técnica as propriedades, limita-se a questões reprodutivas. Demais fatores, como: manejo, nutrição e sanidade são erroneamente negligenciados em segundo plano. A frequência de visitas em assistência ocorre em periodicidade mensal, o que inviabiliza o acompanhamento sanitário. Tal conduta justifica os resultados aqui encontrados, quanto ao número elevado de propriedades com assistência veterinária e ainda sim apresentaram índices elevados de prevalência. Algumas propriedades não possuem assistência 
veterinária $(n=4)$ e dentre as que possuem assistência, o proprietário realiza de forma parcial o que the foi orientado, por questões financeiras ou resistência na implantação de novas tecnologias.

As reações positivas desse estudo podem estar relacionadas com a presença de abortos e de outras doenças reprodutivas nos rebanhos, pode-se indicar que as causas dessas patologias citadas acima podem estar associadas à Leptospira ssp. ou à outras etiologias como: problemas de cunho nutricional e outras doenças abortíferas (Rinotraqueíte Infecciosa Bovina, Diarreia Viral Bovina, Brucelose, Campilobacteriose Genital Bovina).

Tabela 4. Análise dos possíveis Fatores de risco para Leptospirose bovina em rebanhos na mesorregião do Rio Doce/ES.

\begin{tabular}{|c|c|}
\hline Variável & Expostos (\%) \\
\hline \multicolumn{2}{|l|}{ Origem do rebanho } \\
\hline Aberto & 75 \\
\hline Fechado & 25 \\
\hline \multicolumn{2}{|l|}{ Tipo de Exploração } \\
\hline Semi-confinamento & 33 \\
\hline Extensivo & 67 \\
\hline \multicolumn{2}{|l|}{ Tipo de Criação } \\
\hline Leite & 42 \\
\hline Mista & 58 \\
\hline \multicolumn{2}{|l|}{ Existem outras espécies na fazenda } \\
\hline Sim & 58 \\
\hline Não & 42 \\
\hline \multicolumn{2}{|l|}{ Uso de Ocitocina } \\
\hline Sim & 75 \\
\hline Não & 25 \\
\hline \multicolumn{2}{|l|}{ Manejo de Reprodução } \\
\hline IA (Inseminação Artificial) & 0 \\
\hline MN (Monta Natural) & 50 \\
\hline $\mathrm{IA}+\mathrm{MN}$ & 50 \\
\hline Incidência de Abortos & 75 \\
\hline Incidência de Repetição de cio & 50 \\
\hline Incidência de Retenção de Placenta & 25 \\
\hline Incidência de Infertilidade & 50 \\
\hline Presença de pastos alagados & 42 \\
\hline Presença de ratos & 83 \\
\hline Assistência Veterinária & 67 \\
\hline
\end{tabular}

De acordo com o trabalho de Viana \& Zanini (2009) que avaliaram a conduta de realização de vacinação contra doenças infecciosas abortivas bovinas no município de Alegre, região sul do ES, onde das 30 propriedades rurais avaliadas apenas duas vacinavam contra Leptospirose e 18 delas não realizam nenhuma profilaxia contra as enfermidades Brucelose, Leptospirose, Campilobacteriose, Tricomonose, Neosporose, IBR e BVD. Diante dos resultados, a não realização de vacinação anti-Leptospira está intimamente relacionada a ocorrência da doença, pelo fato das propriedades selecionadas não apresentarem esta como profilaxia (Figura 3).

A presença de pastos alagados também pode ser considerada um fator de risco para Leptospirose, onde $42 \%$ propriedades apresentavam áreas alagadas. Associada ao relevo plano e os períodos anuais de chuvas abundantes propiciam o acúmulo de água no solo, tendo importância na manutenção e transmissão do agente.

Por se tratar de uma zoonose com elevada taxa de prevalência em bovinos e dada a falta de conhecimento da doença por parte dos produtores, esta doença necessitaria ser abordada de forma mais 
ampla no meio agropecuário conscientizando os produtores do estado do Espírito Santo sobre seus riscos, prejuízos e formas de prevenção.

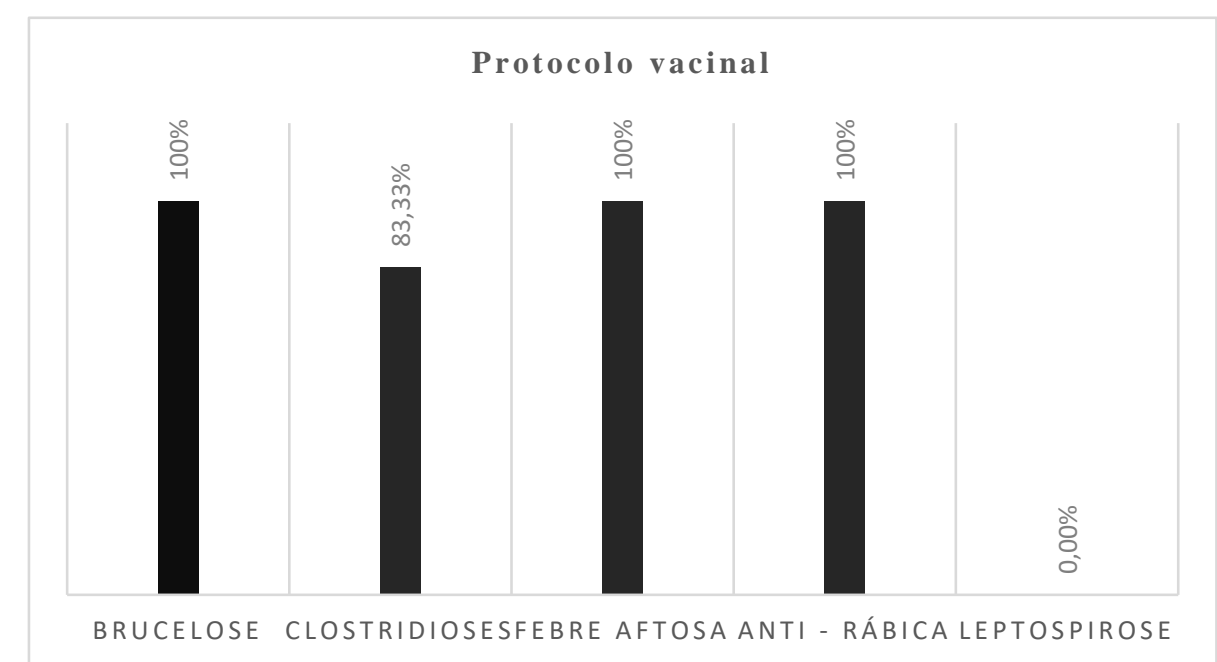

Figura 3. Percentual de propriedades referente ao manejo de vacinação dos 12 rebanhos avaliados na mesorregião do Rio Doce/ES.

\section{Conclusão}

A Leptospira spp. encontra-se sorologicamente presente nos municípios de Aracruz, Ibiraçu, João Neiva, Linhares, Rio Bananal e Sooretama, localizados na Mesorregião do Rio Doce, ES. Com prevalência positiva média de 50\% para Leptospira interrogans. Os sorovares encontrados com maior prevalência foram os sorovares L. Wolffi, seguida da L. Bratislava e L. Hardjo prajitno.

A não vacinação dos animais, a aquisição de animais sem histórico conhecido, a ausência de medidas sanitárias protetivas, manejo de criação conjunta entre diferentes espécies e a presença de roedores podem ser considerados fatores de risco para a doença.

\section{Referências bibliográficas}

ANUALPEC. (2019). Anuário da Pecuária Brasileira (20th ed. Vol. 1). São Paulo, São Paulo, Brasil: Instituto FNP.

Banchiero Júnior, A. M. D., Rezende, L. M., Souza, M. A. \& Lima-Ribeiro, A. M. C. (2014). Levantamento soroepidemiológico de leptospirose em rebanhos bovinos leiteiros no Município de Guaíra-SP. PUBVET, 81698-1821.

Coelho, É. L. M., Chaves, N. P., Sá, J. C., Melo, S. A. \& Silva, A. L. A. (2014). Prevalência de leptospirose em fêmeas bovinas abatidas em frigoríficos no município de São Luís, MA. Brazilian Journal of Veterinary Medicine, 36(2):111-115.

Espírito Santo. Escola de Serviço Público do Espirito Santo - ESESP. Disponível em: <https://esesp.es.gov.br/esesp-em-parceria-com-a-secretaria-de-estado >. Acesso em: 12 março. (2018a).

Espírito Santo. Secretaria de Estado da Agricultura, Abastecimento, Aquicultura e Pesca. Pecuária. Disponível em: <https://incaper.es.gov.br/pecuaria>. Acesso em 21 março. (2018b).

Espírito Santo. Secretaria de Estado da Agricultura, Abastecimento, Aquicultura e Pesca. Pecuária. Disponível em: <https://meteorologia.incaper.es.gov.br/mapas-de-chuva-acumulado-mensal-eanual-2017>. Acesso em: 31 março. (2018c).

Fassio, L. H., Reis, R. P. \& Geraldo, L. G. (2006). Desempenho técnico e econômico da atividade leiteira em Minas Gerais. Ciência e Agrotecnologia, 30(6):1154-1161.

Ferreira, S. B., Sousa, K. R. S., Castro, V., Lopes, S. T. P., Ferreira, S. B., Feitosa, L. C. S. \& Souza, J. A. T. (2017). Análise soroepidemiológica e fatores de risco associados à Leptospira spp. em bovinos no estado do Piauí. Acta Scientiae Veterinariae, 451-11. 
Figueiredo, A. O., Pellegrin, A. O., Gonçalves, V. S. P., Freitas, E. B., Monteiro, L. A. R. C., Oliveira, J. M. \& Osório, A. L. A. R. (2009). Prevalência e fatores de risco para a leptospirose em bovinos de Mato Grosso do Sul. Pesquisa Veterinária Brasileira, 29(5):375-381.

Guimarães, R. M., Cruz, O. G., Parreira, V. G., Mazoto, M. L., Vieira, J. D. \& Asmus, C. I. R. F. (2014). Análise temporal da relação entre leptospirose e ocorrência de inundações por chuvas no município do Rio de Janeiro, Brasil, 2007-2012. Ciência \& Saúde Coletiva, 193683-3692.

Hagiwara, M. K., Miotto, B. A. \& Kogika, M. M. (2015). Leptospirose. In M. M. Jericó, J. P. A. Neto \& M. M. Kogika (Eds.), Tratado de medicina interna de cães e gatos (pp. 2678-2708). Rio de Janeiro, Brasil: Roca.

Homem, V. S. F., Heinemann, M. B., Moraes, Z. M., Vasconcellos, S. A., Ferreira, F. \& Ferreira Neto, J. S. (2001). Estudo epidemiológico da leptospirose bovina e humana na Amazônia oriental brasileira. Revista da Sociedade Brasileira de Medicina Tropical, 34(2):173-180.

Juliano, R. S., Chaves, N. S. T., Santos, C. A. d., Ramos, L. S., Santos, H. Q. d., Meireles, L. R. \& Corrêa Filho, R. A. C. (2000). Prevalência e aspectos epidemiológicos da leptospirose bovina em rebanho leiteiro na microrregião de Goiânia-GO. Ciência Rural, 30(5):857-862.

Lopes, M. A., Santos, G. \& Carvalho, F. M. (2012). Comparativo de indicadores econômicos da atividade leiteira de sistemas intensivos de produção de leite no Estado de Minas Gerais. Ceres, 59(4):458-465.

Marinho, M. (2012). Leptospirose: fatores epidemiológicos, fisiopatológicos e imunopatogênicos. Veterinária e Zootecnia, 15(3):428-434.

Miashiro, A. F., Vasconcelos, S. A., Morais, Z. M., Souza, G. O., Leal Filho, J. M., Figueiredo, A. O. \& Pellegrin, A. O. (2018). Prevalência de leptospirose em rebanhos bovinos no Pantanal de Mato Grosso do Sul. Pesquisa Veterinária Brasileira, 38, n.1, p.41-47, janeiro.(1):41-47.

Nicolino, R. R., Lopes, L. B., Rodrigues, R. O., Teixeira, J. F. B. \& Haddad, J. P. A. (2014). Prevalência e análise espacial de aglutininas antileptospira em gado leiteiro-Microrregião de Sete Lagoas, Minas Gerais, 2009/2010. Arquivo Brasileiro de Medicina Veterinária e Zootecnia, 66(3):648-654.

Oliveira, R. M., Silva, M. L. C. R., Macêdo, M. M. S., Higino, S. S. d. S., Paulin, L. M., Alves, C. J. \& Azevedo, S. S. (2013). Soroepidemiologia da leptospirose e brucelose bovina em propriedades rurais de agricultura familiar do agreste paraibano, Nordeste do Brasil. Arquivos do Instituto Biológico, 80(3):303-311.

Paixão, A. P., Santos, H. P., Alves, L. M. C., Pereira, H. d. M., Carvalho, R. F. B., Costa Filho, V. M. \& Beserra, P. A. (2016). Leptospira spp. em bovinos leiteiros do estado do Maranhão, Brasil: frequência, fatores de risco e mapeamento de rebanhos reagentes. Arquivos do Instituto Biológico, 831-12.

Pimenta, C. L. R. M., Castro, V., Clementino, I. J., Alves, C. J., Fernandes, L. G., Brasil, A. W. L. \& Azevedo, S. S. (2014). Leptospirose bovina no Estado da Paraíba: prevalência e fatores de risco associados à ocorrência de propriedades positivas. Pesquisa Veterinária Brasileira, 34(4):332-336.

Quinn, P. J., Markey, B. K., Carter, M. E., Donnelly, W. J. \& Leonard, F. C. (2005). Microbiologia veterinária e doenças infecciosas. Porto Alegre: Artmed.

Reis, M. d. O., Caprioli, R. A., Laisse, C. J. M., Guimarães, L. L. B., Andrade, C. P., Boabaid, F. M. \& Driemeier, D. (2017). Surto de leptospirose em bezerros criados em resteva de arroz. Pesquisa Veterinária Brasileira, 37(9):937-940.

Sarmento, A., Azevedo, S. S., Morais, Z. M., Souza, G. O., Oliveira, F., Gonçales, A. P. \& Vasconcellos, S. A. (2012). Emprego de estirpes Leptospira spp. isoladas no Brasil na microtécnica de soroaglutinação microscópica aplicada ao diagnóstico da leptospirose em rebanhos bovinos de oito estados brasileiros. Pesquisa Veterinária Brasileira, 32(7):601-606.

Silva, F. J., Conceição, W. L. F., Fagliari, J. J., Girio, R. J. S., Dias, R. A., Borba, M. R. \& Mathias, L. A. (2012). Prevalência e fatores de risco de leptospirose bovina no Estado do Maranhão. Pesquisa Veterinária Brasileira, 32(4):303-312. 
Tonin, A. A., Azevedo, M. I., Escobar, T. P., Casassola, I., Santos, L. G., Cocco, M. \& Badke, M. R. T. (2010). Leptospirose Bovina: Aumento na incidência da Leptospira interogans sorovar butembo no rebanho do estado de Santa Catarina, Brasil. Acta Veterinaria Brasilica, 4(4):294-297.

Viana, K. F. \& Zanini, M. S. (2009). Perfil de produtores frente à vacinação contra doenças infecciosas abortivas em rebanhos bovinos do município de Alegre/ES. Archives of Veterinary Science, 14(2):103-108.

Viana, K. F., Zanini, M. S. \& Moreira, E. C. (2010). Frequência de anticorpos anti-Leptospira spp em rebanhos bovinos da bacia leiteira do Caparaó, estado do Espírito Santo. Archives of Veterinary Science, 15(2):100-106.

Recebido: 25 de setembro, 2019.

Aprovado: 15 de novembro, 2019.

Publicado: 10 de março, 2020.

Licenciamento: Este artigo é publicado na modalidade Acesso Aberto sob a licença Creative Commons Atribuição 4.0 (CC-BY 4.0), a qual permite uso irrestrito, distribuição, reprodução em qualquer meio, desde que o autor e a fonte sejam devidamente creditados.

Anexo. Apêndice - Inquérito epidemiológico.

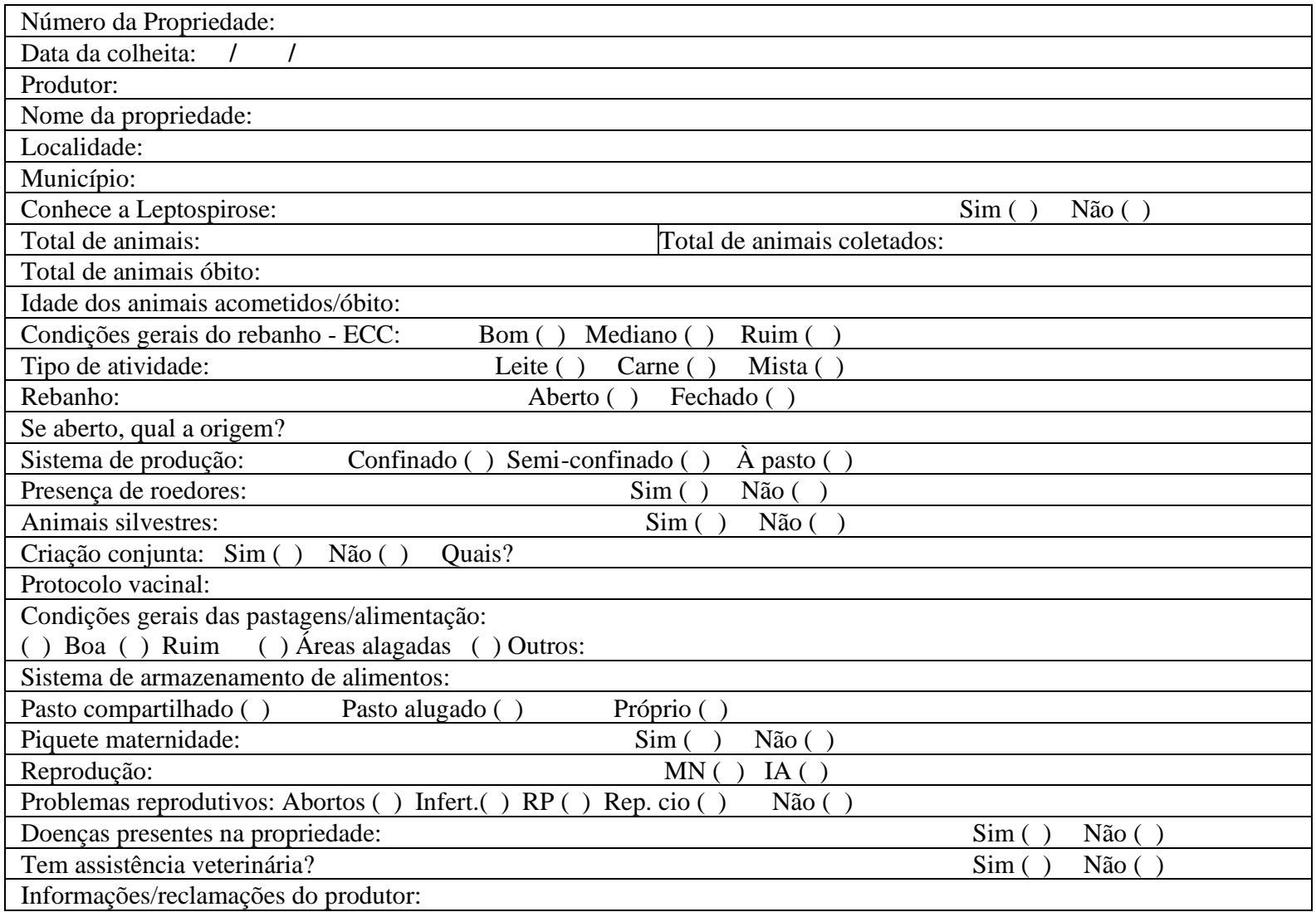

